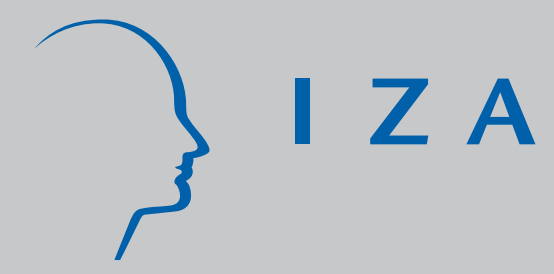

IZA DP No. 1744

\title{
Bargaining and Specialization in Marriage
}

Murat Iyigun

September 2005 


\title{
Bargaining and Specialization in Marriage
}

\author{
Murat lyigun \\ University of Colorado, Boulder, \\ Sabanci University, Istanbul \\ and IZA Bonn \\ Discussion Paper No. 1744 \\ September 2005
}

\author{
IZA \\ P.O. Box 7240 \\ 53072 Bonn \\ Germany \\ Phone: +49-228-3894-0 \\ Fax: +49-228-3894-180 \\ Email: iza@iza.org
}

\begin{abstract}
Any opinions expressed here are those of the author(s) and not those of the institute. Research disseminated by IZA may include views on policy, but the institute itself takes no institutional policy positions.

The Institute for the Study of Labor (IZA) in Bonn is a local and virtual international research center and a place of communication between science, politics and business. IZA is an independent nonprofit company supported by Deutsche Post World Net. The center is associated with the University of Bonn and offers a stimulating research environment through its research networks, research support, and visitors and doctoral programs. IZA engages in (i) original and internationally competitive research in all fields of labor economics, (ii) development of policy concepts, and (iii) dissemination of research results and concepts to the interested public.
\end{abstract}

IZA Discussion Papers often represent preliminary work and are circulated to encourage discussion. Citation of such a paper should account for its provisional character. A revised version may be available directly from the author. 
IZA Discussion Paper No. 1744

September 2005

\section{ABSTRACT}

\section{Bargaining and Specialization in Marriage*}

Can households make efficient choices? The fact that cohabitation and marriage are partnerships for joint production and consumption imply that their gains are highest when household members cooperate. At the same time, empirical findings suggest that spousal specialization and labor force attachment do influence the threat points of each spouse. As a consequence, specialization and spousal cooperation can be costly for household members. While the existing literature is divided on whether household choices are made efficiently or not, there does not yet exist an attempt to identify the marriage market and household dynamics that could induce endogenous cooperation and efficiency within the households. This paper incorporates the process of spousal matching into a household labor supply model in which (a) couples engage in home production, (b) there are potential gains from specialization but specializing in home production lowers market wages, and (c) intra-marital allocations are determined by an endogenous sharing rule that is driven by actual wage earnings. The incentives to specialize are high when wage or spousal endowment inequality is relatively high. Still, when there are equal numbers of men and women in the marriage markets, spousal specialization may not occur unless there exists a commitment mechanism. However, when the sex ratio is not equal to unity and there are singles in equilibrium who are of the same sex as spouses that specialize in market production, matching in asymmetric marriage markets induces spousal cooperation and specialization.

JEL Classification: C78, D61, D70

Keywords: collective model, marriage, matching, household labor supply

Corresponding author:

Murat Iyigun

University of Colorado at Boulder

Department of Economics

Campus Box 256

Boulder, CO 80309-0256

USA

Email: murat.iyigun@colorado.edu

\footnotetext{
* For helpful discussions I thank David Card, Pierre-Andre Chiappori, Zvi Eckstein, Maurizio Mazzocco, Terra McKinnish, Anna Rubinchik-Pessach, Randy Walsh, Yoram Weiss and seminar participants at Koc, Sabanci and Tel Aviv Universities. All errors are my own.
} 


\section{Introduction}

The traditional approach to analyze household choices takes the family as the relevant decision-making unit. ${ }^{1}$ The non-unitary household models provide an alternative to this approach by treating the individual members of the family-not the family as a whole-as the core decision-makers. ${ }^{2}$ Starting in the early $1990 \mathrm{~s}$, the empirical literature began to provide strong support for the notion that relative spousal incomes matter for family decisions and intra-household allocations. ${ }^{3}$ Consequently, the non-unitary household models have emerged as compelling theoretical alternatives for analyzing the economics of the family.

Despite their empirical success, non-unitary models of the household yield different predictions and testable implications depending on whether or not household members can cooperate and make efficient choices. As demonstrated by Chiappori (1988, 1992), Pareto optimality enables one to recover the underlying preference structure of household members as well as the implicit sharing rule that influences the intra-household allocations among different individuals. By confining household choices to those on the Pareto frontier only, however, the so-called collective model also limits the kinds of variables that can influence intra-household allocations. In particular, it is well understood that the sharing rules that help to determine household allocations can only depend on external distribution factors, such as the sex ratios in the markets for marriage, the distributions of non-wage income among men and women, and spousal endowments entering a marriage. ${ }^{4}$

When spousal choices such as labor supply and production specialization influence not only household income but allocations within it, cooperative behavior would be

\footnotetext{
${ }^{1}$ The theoretical foundations of this literature is provided by two seminal papers. In Samuelson (1956), a consensus approach is emphasized as the rationale for treating the household allocation problem as that of maximizing a single household utility function. In Becker (1981), the existence of an altruistic household member is shown to generate outcomes that maximize total family income even in the presence of family members with divergent preferences.

${ }^{2}$ The generalized underpinning of this model is provided by Becker (1981) and Chiappori (1988, 1992). Other examples include Manser and Brown (1980) and MacElroy and Horney (1981).

${ }^{3}$ See, for example, Browning et al. (1994), Chiappori et al. (2002), and Udry (1996).

${ }^{4}$ External distributions factors are variables that can influence intra-household allocations without affecting the spousal choices within marriage. For a relevant discussion, see for example Browning, Chiappori, Lechene (2004).
} 
harder to sustain because it could be costly for household members to commit to efficient choices. Indeed, there are some empirical findings to suspect that spousal specialization and labor force attachment influence the threat points of each spouse. For example, married men work longer hours in the market and have substantially higher wages than unmarried men, and married women work less and have lower wages compared to single women (which together suggest that wives who commit most or all of their time to domestic production could be worse off in divorce). ${ }^{5}$ Of course, when spousal choices affect the household balance of power, one can no longer restrict attention to the efficient frontier. In that case, a plausible alternative is to model spousal behavior as a noncooperative bargaining process. ${ }^{6}$ The major drawback of this approach is that household allocations are likely to be inefficient, which in turn makes it impossible to recover the preferences of household members and the sharing rules that determine intra-household allocations.

As the popularity of the unitary model began to wane in favor of the non-unitary household models, examining the conditions under which efficient household decisions can be attained and identifying the determinants of intra-household sharing rules or household decision making power became more of a pressing matter. And there are both theoretical and empirical reasons for this. On the one hand, theorists need to contend with the choice between the collective and the non-cooperative bargaining models. Choosing the collective model means that spousal choices following marriage-or how those choices could or could not alter allocations within it-have to be restricted. Relying on a non-cooperative bargaining framework often implies limited empirical value due to the likelihood that inefficient outcomes can be sustained; this makes it impossible to

\footnotetext{
${ }^{5}$ See Gronau (1986), Daniel (1992), and Korenman and Neumark (1992). For a detailed overview, also see Weiss (1997).

On a related note, it is possible-at least theoretically-that the returns to domestic skill accumulation is high enough that the partner who specializes in domestic production is better off (or no worse off) in case of divorce than he/she could be without specialization. For this to matter and not adversely affect the bargaining power of the spouse whose time is predominantly allocated to domestic work, however, it ought to be the case that either remarriage is ensured or full specialization in domestic production is optimal even for singles. Neither of these two cases is empirically valid, which lends further credence to the notion that spousal specialization could alter the household balance of power.

${ }^{6}$ For relevant examples, see Lundberg and Pollak (1993, 1994, 2003), Basu (2001), and Iyigun and Walsh (2002).
} 
recover the preferences of household members. On the other hand, empirical studies of household behavior have to deal with the fact that spousal labor supply choices can influence the household balance of power. One less-than-ideal solution to this complication is to acknowledge that labor income can influence household allocations but then to constrain labor supply choices and assume separability between consumption and leisure. In short, while the choice of modelling continues to plague theorists and empiricists alike, the existing methodological approach consists of making an assumption about the efficiency of household choices and then utilizing theoretical and empirical models consistent with that assumption.

In this paper, I establish the conditions under which cooperative versus noncooperative household behavior can be sustained as endogenously-determined marriage market outcomes. By doing so, I am also able to identify the determinants of maritally sustainable and endogenous intra-household sharing rules. In order to accomplish these things, I incorporate the process of spousal matching into a household model in which couples engage in domestic (home) production, there are potential gains from and costs of spousal specialization and intra-marital allocations are determined by an endogenous sharing rule that is driven by actual wage earnings. ${ }^{7}$ The model features home production and spousal specialization because they are two well-established economic benefits of marriage; their existence motivates partnership formation and some degree of spousal cooperation. And consistent with the empirical evidence cited above, the model incorporates a wage premium for labor force attachment and a penalty for specialty in home production. $^{8}$

According to the model, the incentives to specialize are high when wage or spousal endowment inequality is relatively high. In spite of this, when there are equal numbers of men and women in the marriage markets, spousal specialization may not occur unless

\footnotetext{
'In general, the existence of home production does not alter the conclusion that household members' preferences can be identified; Chiappori (1997) shows that, as long as the domestic and market labor supplies are observable, spousal preferences and the intra-household allocation rule can be derived (up to an additive constant).

${ }^{8} \mathrm{I}$ do not explicitly model divorce although the essence of what is derived below would be applicable in an extension that allows for it. In two other papers, Chiappori-Iyigun-Weiss (2004, 2005), we investigate other related implications of divorce on marriage and household allocations.
} 
there exists a commitment mechanism. However, when the sex ratio is not equal to unity and there are singles in equilibrium who are of the same sex as spouses that specialize in market production, matching in asymmetric marriage markets induces spousal cooperation and specialization. In such cases, intra-marital allocations are determined only by the sex ratio in the marriage market, the spousal wage rates, and the distributions of endowment among men and women in the markets for marriage. In sum, my main findings are that the process of marital matching in the large marriage markets (a) can sustain cooperative spousal behavior and (b) help to identify the determinants of intra-household allocations. ${ }^{9}$

These findings suggest that neither strategic, non-cooperative interactions between the spouses nor the endogeneity of intra-marital sharing rules with respect to spousal choices made during the marriage need to be accounted for if the marriage markets are large and the external distribution factors are asymmetric. The reason is that, marriage market competition helps to ensure that each spouse is compensated according to his or her marginal contribution to the marriage and that household decisions are efficient. To state it more broadly, marriage is a partnership for joint production and consumption and its gains are highest when household members cooperate rather than compete. Nonetheless, the general consensus is that, since marriage generates a surplus, partnerships could be sustained even with some degree of non-cooperation and spousal competition. The main finding of this paper is that marriage market competition and the gains from spousal specialization can help to ensure that non-cooperative behavior is eliminated and the gains from partnership and marriage are maximized.

\footnotetext{
${ }^{9}$ In general, models in which spousal matches occur without any frictions (i.e. where all meetings between feasible matches lead to a union) yield different implications than those like Hadfield (1999), Baker-Jacobsen (2003), and Chiappori-Weiss $(2000,2004)$, in which there exists frictions in the marital matching process (as a result of which not all meetings lead to marriages). While both approaches have their own merits, models with frictions generally help to sustain inefficient choices. It is important to note that this is not the case here. While I model spousal matching in the marriage markets as a frictionless process, the endogenously-sustained efficiency result depends on the existence of singles in equilibrium. As such, the main conclusions of the model below would remain intact in models with spousal search frictions (to the extent that it has a higher propensity to yield singles in equilibrium than models without frictions).
} 


\section{Related Literature}

There are various strands in the economics of the family literature to which this paper is related. Of course, the main one is the "collective" household model, which encompasses the early- and late-generation marital bargaining theories. In general, the collective household model allows for differences between spousal preferences to affect household choices by relying on an intra-household sharing rule. Its special case, the noncooperative bargaining model, generates the same feature via Nash-bargaining weights that are exogenous to spousal choices. Among the earliest examples of the collective models are Becker (1981), Chiappori (1988, 1992), and Bourguignon and Chiappori (1994), and those of marital bargaining are Manser and Brown (1980), McElroy and Horney (1981), and Sen (1983). All of these models assume and rely on the fact that the sharing rule or the bargaining power of spouses are determined exogenously (or endogenously but based on external distribution factors). As a consequence, they all yield Pareto efficient intra-household allocations.

At least on a theoretical basis, it is not clear that spousal bargaining power (or the shares spouses extract from marital output) should be a function of potential relative spousal earnings and not actual relative labor income. Taking this distinction seriously, Basu (2001) and Iyigun-Walsh (2002) suggest models that treat the bargaining power of the spouses as determined endogenously according to actual relative earnings. Due to the fact that neither of these models consider and endogenize spousal matching, however, they both yield inefficient household choices and allocations.

Even in models where spousal wealth is a public good in marriage, inefficient allocations and choices can result. But as Peters and Siow (2002) have shown convincingly, families make investments in education that are Pareto optimal once marital matching is endogenized. According to their results, assortative matching and bilateral efficiency together guarantee that, in the large marriage markets, the equilibrium distribution of pre-marital investments are efficient. This is due to the fact that, when spousal wealth is a public good in marriage, the competitive marriage market and the assortative matching that occurs within it guide families to indirectly and reciprocally compensate each other for the investments that they make in their own children. What I present here 
differs Peters and Siow on three accounts: (a) spousal endowments are not public goods; (b) household choices are based on an intra-household allocation mechanism; and (c) spouses recognize that their labor supply decisions influence intra-marital allocations.

This paper is most similar to Becker-Murphy (2000), Browning-Chiappori-Weiss (2003) and Iyigun-Walsh (2004). All three represent the early attempts to broaden the collective approach to cover aspects of household formation that precede marriage. Becker-Murphy and Browning-Chiappori-Weiss share similarities in that they both merge the collective household model with marital sorting to explore the implications of spousal matching. In neither paper, however, there is spousal specialization and endogenous labor supply. Hence, households always make Pareto efficient choices. In Iyigun and Walsh we extend the collective model to cover pre-marital investments and marital sorting. We find that matching in the marriage markets helps to generate unique sharing rules that support unconditionally Pareto efficient outcomes (where both intra-household allocations and pre-marital choices are Pareto efficient).

The remainder of this paper is organized as follows: In section 3, I present some of the basics and discuss the choices of single men and women. The results derived in that section help to establish the reservation levels of utility in marriage. In Section 4, I derive the Pareto efficient frontier of a representative couple. In Section 5, I discuss the equilibrium outcome that would attain for that same couple. In Section 6, I establish who marries whom. In Section 7, I review the implications of spousal matching on household choices. In Section 8, I conclude.

\section{The Basic Model}

Let there be a continuum of men, whose endowments $y_{m}$ are distributed over the income support $[\gamma, Y]$ according to some distribution $G$, and a continuum of women, whose endowments $y_{f}$ are distributed over the same support according to the distribution $H .^{10}$ Normalize the measure of all men in the population to one and denote that of women

\footnotetext{
${ }^{10} \mathrm{I}$ do not address how these spousal endowments might be influenced by pre-marital choices made by individuals in anticipation of marriage. As stated in Section 2, we examine this issue in Iyigun and Walsh (2004). The main finding that emerges is that marriage market competition guides individuals to choose efficient investments in augmenting their endowments prior to entering the marriage markets.
} 
by $r, r \lesseqgtr 1 .^{11}$

Now consider a modified version of the model specified in Weiss (1997, Section 5.3). According to Weiss' taxonomy, there are four broadly defined economic reasons for marriage: (i) division of labor to exploit comparative advantage and increasing returns; (ii) internal supply of credit and coordination of spousal investment; (iii) the sharing of collective (non-rival goods); and (iv) risk management via income pooling. In order to maintain some degree of simplicity, I focus on the spousal specialization/increasing returns aspect as well as the marital sharing of a collective/non-rival good. Accordingly, the utility of a man is

$$
U=h c_{m}
$$

and the utility of a woman is

$$
V=h c_{f}
$$

where $h$ denotes the consumption of household goods and where $c_{i}$ represents person $i$ 's consumption of purchased goods $i, i=f, m$.

If a man and a woman partner up, they share the household good and get the same utility from it, $h$. For a couple, the household budget constraint is

$$
c_{m}+c_{f}=w_{m}\left(1-l_{m}\right) y_{m}+w_{f}\left(1-l_{f}\right) y_{f}
$$

where $l_{m}$ and $l_{f}$ represent the time allocations of the husband and the wife to domestic production respectively and $w_{m}$ and $w_{f}$ represent the market wage rates for the husband and the wife. For single individuals, (2) simplifies to

$$
c_{i}=w_{i}\left(1-l_{i}\right) y_{i}, \quad i=m, f .
$$

Now consider the following technology for the production of the domestic goods:

\footnotetext{
${ }^{11}$ Thus, $r$ equals one if there are equal measures of men and women and it is less (greater) than one if there are less (more) women than men.
} 
Definition 1: (i) For a couple, $h=h\left(l_{m} y_{m}, l_{f} y_{f}\right)=\left(l_{m} y_{m}+l_{f} y_{f}\right)^{\alpha}, 0<\alpha<1$. (ii) By extension, for a single man $h=h\left(l_{m} y_{m}, 0\right)=\left(l_{m} y_{m}\right)^{\alpha}$ and for a single woman $h=$ $h\left(0, l_{f} y_{f}\right)=\left(l_{f} y_{f}\right)^{\alpha}$.

The essential feature of the problem is the interaction in the traits that a couple brings to home production in particular and their marriage in general. As BeckerMurphy and Browning-Chiappori-Weiss note, when endowments are the only important trait and the couple shares a public good, spousal attributes are complements in marital production. The fact that couples share a public good in marriage creates gains from marriage and marital surplus will be positive unless one (or both) of the spouses has (have) no endowment. Given Definition 1 and the utility specifications in equations (1) and (2), this will hold here as well: spousal endowments will be complements and, as we shall establish below, marriage markets will involve assortative matching.

Let $l_{i}^{S}, i=f, m$, denote the optimal amount of time single men and women allocate to home production. The maximization problem of a single man is given by

$$
\max _{l_{m}} U^{S}=h\left(l_{m} y_{m}, 0\right) c_{m}=\left(l_{m} y_{m}\right)^{\alpha} w_{m}\left(1-l_{m}\right) y_{m}
$$

And the maximization problem of a single woman is given by

$$
\max _{l_{f}} V^{S}=h\left(0, l_{f} y_{f}\right) c_{f}=\left(l_{f} y_{f}\right)^{\alpha} w_{f}\left(1-l_{f}\right) y_{f}
$$

Remark 1: The indirect utility level of single men and women equal:

$$
U^{S}=h\left(l_{m}^{S} y_{m}, 0\right) c_{m}^{S}=\beta w_{m} y_{m}^{1+\alpha} \quad \text { and } \quad V^{S}=h\left(0, l_{f}^{S} y_{f}\right) c_{f}^{S}=\beta w_{f} y_{f}^{1+\alpha}
$$

where $\beta \equiv \alpha^{\alpha} /(1+\alpha)^{1+\alpha}$ and where implicitly we have $l_{m}^{S}=l_{f}^{S}=\alpha /(1+\alpha), c_{m}^{S}$ $=w_{m} y_{m} /(1+\alpha)$, and $c_{f}^{S}=w_{f} y_{f} /(1+\alpha)$. 
Proof: Follows immediately from the fact that $l_{i}^{S}, i=f, m$, are the solutions to (5) and (6).

\section{The Pareto Efficient Frontier}

For any couple $\left(y_{m}^{*}, y_{f}^{*}\right)$, the efficient levels of labor supply and intra-household allocations of consumption can be derived by solving the following maximization problem:

$$
\max _{\left\{l f, l_{m}, c_{f}, c_{m}\right\}} U+V=h\left(l_{m} y_{m}^{*}, l_{f} y_{f}^{*}\right)\left(c_{m}+c_{f}\right)
$$

subject to Definition 1,

$$
c_{m}+c_{f} \leq w_{m}\left(1-l_{m}\right) y_{m}+w_{f}\left(1-l_{f}\right) y_{f}
$$

and,

$$
l_{m} \leq 1 \quad \text { and } \quad l_{f} \leq 1
$$

Thus, for the couple $\left(y_{m}^{*}, y_{f}^{*}\right)$, the Pareto efficient frontier is characterized by the following first-order conditions:

$$
\frac{\alpha\left[w_{m}\left(1-l_{m}\right) y_{m}^{*}+w_{f}\left(1-l_{f}\right) y_{f}^{*}\right]}{l_{m} y_{m}^{*}+l_{f} y_{f}^{*}}-w_{m} y_{m}^{*} \leq 0
$$

and,

$$
\frac{\alpha\left[w_{m}\left(1-l_{m}\right) y_{m}^{*}+w_{f}\left(1-l_{f}\right) y_{f}^{*}\right]}{l_{m} y_{m}^{*}+l_{f} y_{f}^{*}}-w_{f} y_{f}^{*} \leq 0 .
$$

Letting $l_{i}^{E}, i=f, m$, denote the Pareto efficient levels of time allocated to home production, we have 
Remark 2: For any couple $\left(y_{m}^{*}, y_{f}^{*}\right)$, the Pareto efficient optimal household choices are such that

(i) $w_{m} y_{m}^{*}>w_{f} y_{f}^{*} \Leftrightarrow l_{m}^{E}=0 \wedge l_{f}^{E} \in(0,1]$;

(ii) $w_{m} y_{m}^{*}<w_{f} y_{f}^{*} \Leftrightarrow l_{m}^{E} \in(0,1] \wedge l_{f}^{E}=0$;

(iii) $w_{m} y_{m}^{*}=w_{f} y_{f}^{*} \quad \Leftrightarrow \quad l_{m}^{E}, l_{f}^{E} \in[0,1]$ with $l_{m}^{E}+l_{f}^{E} \in(0,2)$.

Proof: Follows from the two first-order conditions (11) and (12).

According to Remark 2, the Pareto efficient household choices involve some degree of specialization when the market wage earnings differ between the spouses. In particular, we find that the husband (wife) specializes in market production when his (her) potential wage income exceeds that of his (her) partner's. When that is the case, the other spouse could specialize in home production only depending on parameter values. In contrast, when the wage earnings of the spouses are identical, a continuum of labor supply and home production time allocations generate efficient outcomes (where the only restriction is that the couple allocates a positive amount of time to both home production and market production). For heuristic purposes, I shall assume hereafter that, when wage earnings differ so that there is specialization, each spouse works either in the market or at home and that when the wage earnings are identical, spouses allocate their time between market production and home production as if they were single. ${ }^{12}$

Assumption 1: Parameter values are s.t., $\forall\left(y_{m}^{*}, y_{f}^{*}\right), w_{m} y_{m}^{*}>w_{f} y_{f}^{*} \Leftrightarrow l_{m}^{E}=0 \wedge l_{f}^{E}=$ $1 ; w_{m} y_{m}^{*}<w_{f} y_{f}^{*} \Leftrightarrow l_{f}^{E}=0 \wedge l_{m}^{E}=1 ;$ and $w_{m} y_{m}^{*}=w_{f} y_{f}^{*} \Leftrightarrow l_{m}^{E}=l_{f}^{E}=\alpha / 1+\alpha$.

The last important piece of our model involves the notion that specialization in home production can be costly and that the market wage of married individuals is higher than those of singles. This leads to our second assumption:

\footnotetext{
${ }^{12}$ While these restrictions are not necessary, I make them for the purpose of expositional ease. Moreover, they can be justified on the premise that time allocation decisions are lumpy; either a person can work full time in a market activity or half time. The restriction that specialization always involves a spouse devoting full time to market production and the other full time to home production can alternatively be generated via parameter restrictions.
} 
Assumption 2: (i) If a spouse specializes in home production and then begins to work in the market, his or her market wage rate equals $w_{i}^{h}, w_{i}^{h}<w_{i}, i=f, m$; (ii) the market wage rate of an individual who specializes in market production equals $w_{i}^{p}$, $w_{i}^{p}>w_{i}, i=f, m$.

The justification for Assumption 2 is provided by the findings of Gronau (1986), Daniel (1992), and Korenman-Neumark (1992), who document that married men work longer than their single counterparts and have substantially higher wages than unmarried men. They also show that married women work less and have lower wages compared to single women. The main implication of this assumption is that specialization in home production is costly and labor force attachment is beneficial. ${ }^{13}$

Now let $c_{i}^{E}, i=f, m$, denote the efficient spousal consumption levels and $U^{E}$ and $V^{E}$ represent the indirect utility levels consistent with the Pareto efficient allocations. On the basis of Assumption 1 and the three cases presented in Remark 2, the Pareto efficient household outcomes will be as follows:

Remark 3: (i) If $w_{m} y_{m}^{*}>w_{f} y_{f}^{*}$, then $l_{m}^{E}=0$ and $l_{f}^{E}=1$. Hence, we have $h=\left(y_{f}^{*}\right)^{\alpha}, c_{f}^{E}$ $+c_{m}^{E}=w_{m}^{p} y_{m}^{*}$ and $U^{E}+V^{E}=\left(y_{f}^{*}\right)^{\alpha} w_{m}^{p} y_{m}^{*}$

(ii) If $w_{m} y_{m}^{*}<w_{f} y_{f}^{*}$, then $l_{m}^{E}=1$ and $l_{f}^{E}=0$. Hence, we have $h=\left(y_{m}^{*}\right)^{\alpha}, c_{f}^{E}+c_{m}^{E}$ $=w_{f}^{p} y_{f}^{*}$ and $U^{E}+V^{E}=\left(y_{m}^{*}\right)^{\alpha} w_{f}^{p} y_{f}^{*}$;

(iii) If $w_{m} y_{m}^{*}=w_{f} y_{f}^{*}$, then $l_{m}^{E}=l_{f}^{E}=\alpha /(1+\alpha)$. Hence, we have $h=\left[\alpha\left(y_{m}^{*}+y_{f}^{*}\right) /(1+\right.$ $\alpha)]^{\alpha}, c_{f}^{E}+c_{m}^{E}=\left(w_{m} y_{m}^{*}+w_{f} y_{f}^{*}\right) /(1+\alpha)$ and $U^{E}+V^{E}=\beta\left(y_{m}^{*}+y_{f}^{*}\right)^{\alpha}\left(w_{m} y_{m}^{*}+w_{f} y_{f}^{*}\right)$.

The basic point here is that, when the couple $\left(y_{m}^{*}, y_{f}^{*}\right)$ makes its decisions efficiently, consumption choices can be separated from those regarding labor supply. That is, under efficiency, the couple would choose its labor supply to maximize aggregate household

\footnotetext{
${ }^{13}$ I employ this structure on the basis of the empirical evidence cited above. But there are a number of alternative specifications that would yield results that are similar to those presented here. The only crucial requirement is for the market wage rate to fall upon specialization in domestic production.
} 
utility and then rely on a transfer to regulate the desired and sustainable level of utility for each spouse.

On the basis of Assumption 2 and the optimal patterns of spousal specialization in Remark 3, we can derive the threat points of each spouse conditional on specialization. Let those threat points be represented by $U^{E S}$ and $V^{E S}$ for the husband and the wife respectively. Then, we have

Remark 4: (i) If $w_{m} y_{m}^{*}>w_{f} y_{f}^{*}$, then $l_{m}^{E}=0$ and $l_{f}^{E}=1$. Thus, $U^{E S}=\beta w_{m}^{p}\left(y_{m}^{*}\right)^{1+\alpha}$ and $V^{E S}=\beta w_{f}^{h}\left(y_{f}^{*}\right)^{1+\alpha}$ where $U^{E S}>U^{S}$ and $V^{E S}<V^{S}$

(ii) If $w_{m} y_{m}^{*}<w_{f} y_{f}^{*}$, then $l_{m}^{E}=1$ and $l_{f}^{E}=0$. Thus, $U^{E S}=\beta w_{m}^{h}\left(y_{m}^{*}\right)^{1+\alpha}$ and $V^{E S}$ $=\beta w_{f}^{p}\left(y_{f}^{*}\right)^{1+\alpha}$ where $U^{E S}<U^{S}$ and $V^{E S}>V^{S}$;

(iii) If $w_{m} y_{m}^{*}=w_{f} y_{f}^{*}$, then $l_{m}^{E}=l_{f}^{E}=1 / 2$. Hence, $U^{E S}=\beta w_{m}\left(y_{m}^{*}\right)^{1+\alpha}$ and $V^{E S}=$ $\beta w_{f}\left(y_{f}^{*}\right)^{1+\alpha}$ where $U^{E S}=U^{S}$ and $V^{E S}=V^{S}$.

According to Remark 4, when specialization is warranted $\left(w_{m} y_{m}^{*} \neq w_{f} y_{f}^{*}\right)$ and a partner devotes full time to home production, his (her) threat point in marriage decreases due to the fact that, if (s)he went back to market production, his (her) wage income would be lower. And since upon devoting full time to homework the drop in the market wage is irreversible, this will have an important bearing on whether specialization will occur within the household.

\section{The Household Equilibrium (for a given couple)}

Consider the decision problem faced by a couple with the endowments $\left(y_{m}^{*}, y_{f}^{*}\right)$. According to Remark 3, this couple would gain from specialization in market and home production when $w_{m} y_{m}^{*} \neq w_{f} y_{f}^{*} .{ }^{14}$ Now consider a standard Nash bargaining framework in which the threat points of each spouse influence their consumption allocations. That is, conditional on the choice of production specialization, suppose that the couple determines their consumption levels in the following way:

\footnotetext{
${ }^{14}$ As I show below, given that the marital production function exhibits a complementarity between spousal endowments, marriage will generate a surplus regardless of the pattern of specialization.
} 


$$
\max _{c_{f}, c_{m}}(U-\bar{U})^{\theta}(V-\bar{V})^{1-\theta}=\left(h c_{m}-\bar{U}\right)^{\theta}\left(h c_{f}-\bar{V}\right)^{1-\theta}
$$

where $0<\theta<1$ and where $\bar{U}=U^{E S}$ and $\bar{V}=V^{E S}$ if the couple agrees to specialize and $\bar{U}=U^{S}$ and $\bar{V}=V^{S}$ if it does not.

Since, for the time being, we take the state of their partnership as given, it is straightforward to reveal that spousal specialization would not be sustainable. The next proposition formalizes this observation.

Proposition 1: Taking as given the couple $\left(y_{m}^{*}, y_{f}^{*}\right)$ and in the absence of a commitment mechanism, household equilibrium involves no specialization. Hence, we have $l_{m}^{E}$ $=l_{f}^{E}=\alpha /(1+\alpha), h=\left[\alpha\left(y_{m}^{*}+y_{f}^{*}\right) /(1+\alpha)\right]^{\alpha}, c_{f}^{E}+c_{m}^{E}=\left(w_{m} y_{m}^{*}+w_{f} y_{f}^{*}\right) /(1+\alpha)$ and $U^{E}+V^{E}=\beta\left(y_{m}^{*}+y_{f}^{*}\right)^{\alpha}\left(w_{m} y_{m}^{*}+w_{f} y_{f}^{*}\right)$.

Proof: See Appendix Section 9.1.

We have now established that specialization and spousal cooperation may not be sustainable taking as given a partnership. Next, we endogenize both the spousal matching process and intra-household allocations consistent with marriage market conditions in order to examine what impact, if any, they might have on household decision-making.

\section{The Marriage Market Equilibrium and Household Choices}

So who marries whom? As shown in Remark 3, the combination of home production and the consumption of purchased goods generates a positive interaction between the partners' endowments, creating gains from marriage. As a result, the marriage market equilibrium will involve assortative matching. In particular,

Remark 5: On the basis of equations (1) and (2) and Definition 1, the marriage market generates assortative spousal matching. 
Proof: See Appendix Section 9.2.

With assortative spousal matching, if a man with an endowment of $y_{m}$ is married to a woman with $y_{f}$, then the set of men with incomes above $y_{m}$ must exactly equal the set of women with incomes above $y_{f}$. This implies the following marriage market clearing condition:

$$
1-G\left(y_{m}\right)=r\left[1-H\left(y_{f}\right)\right]
$$

As a result, we have the following spousal matching functions:

$$
y_{m}=\Phi\left\{1-r\left(1-H\left(y_{f}\right)\right]\right\} \equiv \phi\left(y_{f}\right)
$$

and,

$$
y_{f}=\Psi\left\{1-\frac{1}{r}\left(1-G\left(y_{m}\right)\right]\right\} \equiv \psi\left(y_{m}\right)
$$

where $\Phi \equiv G^{-1}$ and $\Psi \equiv H^{-1}$.

All men and women would marry if there is an equal measure of men and women in the marriage market $(r=1)$. All men would get married if there is a scarcity of men $(r>1)$ and all women would marry if there is a scarcity of women $(r<1)$. If $r>$ 1 , women with incomes less than $y_{f}^{0} \equiv \gamma+\Psi(1-1 / r)(Y-\gamma)$ would unambiguously remain single and if $r<1$, men with less than $y_{m}^{0} \equiv \gamma+\Phi(1-r)(Y-\gamma)$ would surely remain single. If $r>1$, the function described by equation (16) pins down the wife of a man with an income of $y_{m}$, and if $r<1$ the function given by (15) identifies the husband of a woman with an income of $y_{f}$. Of course, if $r=1$ and the distributions $G$ and $H$ are identical, $y_{m}=y_{f}$. In sum, either of the functions $\phi\left(y_{f}\right)$ and $\psi\left(y_{m}\right)$ fully describes the nature of spousal matching. 
We are now in position to address what the sustainable marriage market outcomes and equilibrium intra-household allocations look like.

\section{Sustainable Intra-Household Allocations}

With transferable utility, $\forall\left(y_{m}^{*}, y_{f}^{*}\right)$ in the set of married couples, the following three conditions must be satisfied in equilibrium:

1. $1-G\left(y_{m}^{*}\right)=r\left[1-H\left(y_{f}^{*}\right)\right]$;

2. $\forall y_{m}^{*} \in[\gamma, Y], y_{f}^{*}=\arg \max \left[h\left(l_{m} y_{m}^{*}, l_{f} y_{f}^{*}\right)\left(c_{m}+c_{f}\right)-V\right]$

3. $\forall y_{f}^{*} \in[\gamma, Y], y_{m}^{*}=\arg \max \left[h\left(l_{m} y_{m}^{*}, l_{f} y_{f}^{*}\right)\left(c_{m}+c_{f}\right)-U\right]$

Part 1 of the definition is the marriage market-clearing condition defined by equation (14). Parts 2 and 3 indicate that all individuals choose their spouses optimally in order to maximize their gains from marriage. Given Remark 3, spousal wage incomes affect the patterns of efficient specialization within households; this makes marital output dependent on relative spousal wage incomes.

Together with Remark 3, Parts 2 and 3 yield the following conditions respectively: ${ }^{15}$

$$
\begin{array}{cc}
\frac{\partial V}{\partial y_{f}}=\alpha y_{f}^{\alpha-1} w_{m} \phi\left(y_{f}\right) & \text { if } w_{m} \phi\left(y_{f}\right)>w_{f} y_{f} \\
\frac{\partial V}{\partial y_{f}}=\phi\left(y_{f}\right)^{\alpha} w_{f} & \text { if } w_{m} \phi\left(y_{f}\right)<w_{f} y_{m} \\
\frac{\partial V}{\partial y_{f}}=(1+\alpha) w_{m} \phi\left(y_{f}\right) & \text { if } w_{m} \phi\left(y_{f}\right)=w_{f} y_{f},
\end{array}
$$

and,

\footnotetext{
${ }^{15}$ Note that the expressions below represent the first-order conditions after the the envelope theorem is applied.
} 


$$
\begin{aligned}
& \frac{\partial U}{\partial y_{m}}=\psi\left(y_{m}\right)^{\alpha} w_{m} \quad \text { if } w_{m} y_{m}>w_{f} \psi\left(y_{m}\right) \\
& \frac{\partial U}{\partial y_{m}}=\alpha y_{m}^{\alpha-1} w_{f} \psi\left(y_{m}\right) \quad \text { if } w_{m} y_{m}<w_{f} \psi\left(y_{m}\right) \\
& \frac{\partial U}{\partial y_{m}}=(1+\alpha) w_{f} \psi\left(y_{m}\right) \quad \text { if } w_{m} y_{m}=w_{f} \psi\left(y_{m}\right) .
\end{aligned}
$$

We can thus derive the efficient levels of spousal allocations and utility:

Proposition 2: For a couple $\left(y_{m}^{*}, y_{f}^{*}\right)$,

(i) if $w_{m} y_{m}>w_{f} y_{f}$, then

$$
U=k+w_{m} \int_{y_{m}^{0}}^{y_{m}^{*}} \psi(s)^{\alpha} d s \text { and } \quad V=k^{\prime}+\alpha w_{m} \int_{y_{f}^{0}}^{y_{f}^{*}} t^{\alpha-1} \phi(t) d t ;
$$

(ii) if, $w_{m} y_{m}<w_{f} y_{f}$, then

$$
U=k+\alpha w_{f} \int_{y_{m}^{0}}^{y_{m}^{*}} s^{\alpha-1} \psi(s) d s \quad \text { and } \quad V=k^{\prime}+w_{f} \int_{y_{f}^{0}}^{y_{f}^{*}} \phi(t)^{\alpha} d t ;
$$

(iii) and if, $w_{m} y_{m}=w_{f} y_{f}$, then

$$
U=k+(1+\alpha) w_{m} \int_{y_{m}^{0}}^{y_{m}^{*}} \psi(s) d s \quad \text { and } \quad V=k^{\prime}+(1+\alpha) w_{f} \int_{y_{f}^{0}}^{y_{f}^{*}} \phi(t) d t
$$

where the additive constants, $k, k^{\prime}$, are the endogenously-determined utility levels of lowest-ranked husbands and wives respectively (more on which below).

Proof: Follows from integrating equations (17) and (18).

In Figure 1, I depict two different marriage market equilibria (which in general may or may not involve efficient choices, but as drawn implicitly reflect efficiency). In 
accordance with Part 1 of the equilibrium definition, the spousal matching function $\psi\left(y_{m}\right)$ establishes who marries whom. In the figure I show two alternative matching functions where, as usual, a more favorable match for the wives-in the sense that each woman matches with a man with a higher endowment level-raises the wives' intra-marital allocations and leads to a higher utility for them on the Pareto frontier.

[Figure 1 about here.]

There are two important issues here: First, how are the utility levels of lowestranked husbands and wives influenced by the marriage market? And second, does the marriage market equilibrium, which yields the above utility levels for each spouse, induce cooperation and specialization when it is optimal?

According to Proposition 2, if there is an excess supply of men in the marriage market $(r<1)$, then the lowest-ranked husbands (who will have endowments equal to $\gamma$ ) will get their reservation utility levels $-U^{S}$ without specialization and $U^{E S}$ with it. Hence, when $r<1, k=U^{S}$ or $U^{E S}$. A similar logic applies when there is an excess supply of women in the marriage market $(r>1)$, which yields $k^{\prime}=V^{S}$ or $V^{E S}$. When there are equal numbers of men and women in the marriage market $(r=1)$, then all men and women will marry. Without any singles in equilibrium, couples may not specialize even when it is optimal. Consequently, all we can conclude is that, when $r=1, k \geqslant U^{S}$ and $k^{\prime} \geqslant V^{S}$.

Now consider the case in which either (i) $r>1$ and $w_{m} y_{m}>w_{f} y_{f}$ or (ii) $r<1$ and $w_{m} y_{m}<w_{f} y_{f}$. In case (i), there are more women than men in the marriage market and it is optimal for the husband to specialize in market activities and the wife in home production. In case (ii), the opposite holds; there are more men than women and the wives ought to specialize in market production and the husbands in homework. However, it is easy to verify that specialization cannot be sustained even though it is warranted in either case. The reason for this is simple: Specialization in homework is taxing and that in market production is rewarding and there is an excess supply of spouses that ought to devote all of their time to home production. This implies that, among the 
lowest-ranked couples, spouses that would specialize in domestic work would get their reservation utility level. In case (i), if the couple specializes, we get $k^{\prime}=V^{E S}$ and if it does not we get $k^{\prime}=V^{S}$. Since, in this case, $V^{S}=\beta w_{f}\left(y_{f}^{*}\right)^{1+\alpha}>V^{E S}=\beta w_{f}^{h}\left(y_{f}^{*}\right)^{1+\alpha}$, we establish that the wives in lowest-ranked marriages would not be willing to specialize. And, as an extension, this would carry higher up in the assortative order so that no couple can sustain specialization. The only difference in case (ii) is that husbands ought to specialize in domestic production but they don't so that $k=U^{S}=\beta w_{m}\left(y_{m}^{*}\right)^{1+\alpha}>$ $U^{E S}=\beta w_{m}^{h}\left(y_{m}^{*}\right)^{1+\alpha}$.

In contrast, consider what happens if either (iii) $r<1$ and $w_{m} y_{m}>w_{f} y_{f}$ or (iv) $r>1$ and $w_{m} y_{m}<w_{f} y_{f}$. In case (iii), there are more men than women in the marriage market and it is optimal for the husband to specialize in market activities and the wife in home production. In case (iv), there are more women than men and the wives should specialize in market production and the husbands in homework. Marriage market equilibrium ensures that the excess-sex spouses in the lowest-rank marriages receive the same utility levels as the similarly-endowed, same-sex singles. In case (iii) husbands are more abundant so they would get $U^{S}$, and in case (iv), wives are more abundant and they would receive $V^{S}$. The interesting point here is that, in case (iii), husbands would not receive $U^{E S}=\beta w_{m}^{p}\left(y_{m}^{*}\right)^{1+\alpha}$ even when they specialize in market activities-as efficiency would dictate. Instead, they would get $U^{S}=\beta w_{m}\left(y_{m}^{*}\right)^{1+\alpha}<U^{E S}$ due to the fact that there exist single men with identical endowments in equilibrium. Their presence is sufficient to ensure that married men with similar endowments not only receive no marital surplus but also specialize in market production. Of course, the same logic applies to married women in case (iv). Hence, we can establish that, in both cases, lowest-rank couples specialize efficiently.

What does this imply for higher-ranked couples? If the availability of singles enforces efficient choices among lowest-rank couples, then it is not possible for couples in higher ranks to sustain non-cooperative household choices either. The reason is similar to the one which generates efficiency in the lowest ranks: for any couple ranked slightly above the lowest-ranked couples, marital surplus could be raised by either spouse in such a marriage partnering with someone of a slightly lower rank-who in his or her 
existing partnership is abiding by efficient choices. By doing so, both new partners could be made better off. Thus, if lower-ranked couples are efficient decision-makers, slightly higher ranked marriages will not be able to sustain non-cooperative marriages. As the next proposition shall show, however, this does not mean that all excess-sex spouses along the assortative order will get their reservation utility; only those in the lowest ranks will as the equilibrium allocations specified in Proposition 2 ensure that all partners receive their marginal contributions to the marital output and surplus.

Proposition 3: (i) if $r<1$ and $w_{m} y_{m}>w_{f} y_{f}$, then, $\forall\left(y_{m}^{*}, y_{f}^{*}\right), l_{m}^{E}=0, l_{f}^{E}=1, h=$ $\left(y_{f}^{*}\right)^{\alpha}, c_{f}^{E}+c_{m}^{E}=w_{m}^{p} y_{m}^{*}$ and $U^{E}+V^{E}=\left(y_{f}^{*}\right)^{\alpha} w_{m}^{p} y_{m}^{*}$ with $U^{E}$ and $V^{E}$ determined by part (i) in Proposition 2;

(ii) if $r>1$ and $w_{m} y_{m}<w_{f} y_{f}$, then, $\forall\left(y_{m}^{*}, y_{f}^{*}\right), l_{m}^{E}=1, l_{f}^{E}=0, h=\left(y_{m}^{*}\right)^{\alpha}, c_{f}^{E}+$ $c_{m}^{E}=w_{f}^{p} y_{f}^{*}$ and $U^{E}+V^{E}=\left(y_{m}^{*}\right)^{\alpha} w_{f}^{p} y_{f}^{*}$ with $U^{E}$ and $V^{E}$ determined by part (ii) in Proposition 2;

(iii) in both cases, intra-household sharing rules are functions of only the sex ratio $r$, spousal wage rates $w_{i}, i=f, m$, and the distribution of spousal endowment levels, $y_{i}, i=f, m$.

Proof: See Appendix Section 9.3.

Figure 2 illustrates the maritally sustainable outcomes that attain when $r<1$ and $w_{m} y_{m}>w_{f} y_{f}$. In the figure, the marital outcome for couples at two different points in the assortative order are depicted; one couple is of the lowest rank and the other is of a higher rank. For both couples, the marriage market yields Pareto efficient and sustainable outcomes. ${ }^{16}$ However, the husband of the lowest-rank couple can only attain his reservation utility level, denoted as $U^{S}$, because there are fewer women in the marriage market. For this couple, the marriage market outcome is given by point $A$ on

\footnotetext{
${ }^{16}$ The exact shape of the marital contract curve is not readily established, but we can ascertain that, since efficient sharing mechanism described in Proposition 2 yields unique solutions, the efficient frontier and the marital contract curve intersect at only one point.
} 
their marital contact curve. In contrast, the husband of any higher ranked couple (and in particular the one shown in the figure) attains a higher utility than his reservation level, $U^{S}$. This is due to the fact that marital production exhibits complementarities in spousal endowments and, as implied by Proposition 2, partners get their marginal contributions to the marriage. For this couple, the marriage market outcome is point $C$ on their marital contract curve.

[Figure 2 about here.]

As a final point note the following: The sustainability of non-cooperative, inefficient allocations requires that all couples behave non-cooperatively in equilibrium when $r=$ 1. As the preceding discussion verifies, if there exists at least some couples that make efficient household choices, then all couples will be forced to make such choices because marriage market competition-based on the above mechanism-would make the existing partnership structure unsustainable. Thus, when $r=1$ and all individuals are married in equilibrium, either all couples behave non-cooperatively and live with inefficient outcomes or they all make efficient choices.

\section{Conclusion}

In analyzing intra-marital family decisions, the non-unitary household models treat each individual family member-as opposed to the whole family-as the relevant decision making unit. Empirical studies carried out in the last decade or so have provided consistent support for the idea that relative spousal incomes matter for family decisions and intrahousehold allocations. Hence, the non-unitary approach to household decision-making has emerged as the compelling theoretical tool for analyzing the economics of the family.

The empirical implications of the non-unitary household models hinges on whether couples can reach Pareto efficient decisions. But can households make such choices and if yes under what conditions? On the one hand, the fact that cohabitation and marriage are partnerships for joint production and consumption imply that their gains are highest when household members cooperate. At the same time, empirical findings 
suggest that spousal specialization and labor force attachment do influence the threat points of each spouse. As a consequence, specialization and spousal cooperation can be costly for household members. As I have argued in the introduction, this issue has still not been resolved satisfactorily and continues to puzzle theorists and empiricists alike. The consensus approach consists of making an assumption about the efficiency of household choices and then utilizing theoretical and empirical models consistent with that assumption.

I had two main goals in this paper. One was to establish the conditions under which cooperative versus non-cooperative household behavior can be sustained as endogenously-determined marriage market outcomes. Two, on the basis of equilibrium household behavior, I wanted to identify the determinants of maritally sustainable and endogenous intra-household sharing rules. To that end, I incorporated the process of spousal matching into a spousal labor supply model in which couples engage in home production, there are potential gains from specialization but specializing in home production lowers market wages, and intra-marital allocations are determined by an endogenous sharing rule that is driven by actual wage earnings. The incentives to specialize are high when wage or spousal endowment inequality is relatively high. When there are equal numbers of men and women in the marriage markets, spousal specialization may not occur unless there exists a commitment mechanism. However, when the sex ratio is not equal to unity and there are singles in equilibrium who are of the same sex as spouses that specialize in market production, matching in asymmetric marriage markets induces spousal cooperation and specialization. In such cases, the maritally sustainable intrahousehold sharing rules are not only unique but also functions of only the sex ratio, spousal wage rates and the distribution of spousal endowments.

In sum, I have identified that neither strategic spousal interactions nor the endogeneity of intra-marital sharing rules with respect to spousal choices made during the marriage need to be accounted for if the marriage markets are large and the external distribution factors are asymmetric. Then, the efficiency of household choices are generally restored because marriage market competition can help to ensure that each spouse is compensated according to his or her marginal contribution to the marriage. 


\section{Appendix}

\subsection{Proof of Proposition 1:}

For illustrative purposes, take the case in which $w_{m} y_{m}^{*}<w_{f} y_{f}^{*}$. If the couple $\left(y_{m}^{*}, y_{f}^{*}\right)$ chooses to specialize, the first-order conditions for the solution to the problem in (13) yield the following equality:

$$
\frac{h c_{f}^{E}-V^{E S}}{h c_{m}^{E}-U^{E S}}=\frac{\left(y_{m}^{*}\right)^{\alpha} c_{f}^{E}-\beta w_{f}^{p} y_{f}^{1+\alpha}}{\left(y_{m}^{*}\right)^{\alpha} c_{m}^{E}-\beta w_{m}^{h} y_{m}^{1+\alpha}}=\frac{\theta}{1-\theta} .
$$

If the couple $\left(y_{m}^{*}, y_{f}^{*}\right)$ does not specialize, the first-order conditions for the solution to the problem in (13) yield the following:

$$
\frac{h c_{f}^{S}-V^{S}}{h c_{m}^{S}-U^{S}}=\frac{\left[\frac{\alpha\left(y_{m}^{*}+y_{f}^{*}\right)}{1+\alpha}\right]^{\alpha} c_{f}^{S}-\beta w_{f} y_{f}^{1+\alpha}}{\left[\frac{\alpha\left(y_{m}^{*}+y_{f}^{*}\right)}{1+\alpha}\right]^{\alpha} c_{m}^{S}-\beta w_{m} y_{m}^{1+\alpha}}=\frac{\theta}{1-\theta} .
$$

Based on (9.1.1) and (9.1.2), we get

$$
\frac{\left(y_{m}^{*}\right)^{\alpha} c_{f}^{E}-\beta w_{f}^{p} y_{f}^{1+\alpha}}{\left[\frac{\alpha\left(y_{m}^{*}+y_{f}^{*}\right)}{1+\alpha}\right]^{\alpha} c_{f}^{S}-\beta w_{f} y_{f}^{1+\alpha}}=\frac{\left(y_{m}^{*}\right)^{\alpha} c_{m}^{E}-\beta w_{m}^{h} y_{m}^{1+\alpha}}{\left[\frac{\alpha\left(y_{m}^{*}+y_{f}^{*}\right)}{1+\alpha}\right]^{\alpha} c_{m}^{S}-\beta w_{m} y_{m}^{1+\alpha}} .
$$

Since $w_{m}^{h}<w_{m}$ and $w_{f}^{p}>w_{f}$, we conclude that, for any given $\theta, \exists w^{p}, w^{h}$ such that $\left(y_{m}^{*}\right)^{\alpha} c_{m}^{E}<\left[\alpha\left(y_{m}^{*}+y_{f}^{*}\right) /(1+\alpha)\right]^{\alpha} c_{m}^{S}$ and $\left(y_{m}^{*}\right)^{\alpha} c_{f}^{E}>\left[\alpha\left(y_{m}^{*}+y_{f}^{*}\right) /(1+\alpha)\right]^{\alpha} c_{f}^{S}$. In words, the equilibrium intra-household allocation of the husband one he commits to specialization is strictly less than his allocation when he does not agree to specialize in home production. This shows that a commitment to an allocation of $U^{S}$ by the wife is not time consistent. Thus, the couple will choose not to specialize and $l_{m}^{E}=l_{f}^{E}=$ $\alpha /(1+\alpha), h=\left[\alpha\left(y_{m}^{*}+y_{f}^{*}\right) /(1+\alpha)\right]^{\alpha}, c_{f}^{E}+c_{m}^{E}=\left(w_{m} y_{m}^{*}+w_{f} y_{f}^{*}\right) /(1+\alpha)$ and $U^{E}+V^{E}$ $=\beta\left(y_{m}^{*}+y_{f}^{*}\right)^{\alpha}\left(w_{m} y_{m}^{*}+w_{f} y_{f}^{*}\right)$. 


\subsection{Proof of Remark 5:}

Marital output equals $U^{E}+V^{E}=y_{f}^{\alpha} w_{m} y_{m}$ when $w_{m} y_{m}>w_{f} y_{f}$; it equals $U^{E}+V^{E}$ $=y_{m}{ }^{\alpha} w_{f} y_{f}$ when $w_{m} y_{m}<w_{f} y_{f}$; and it equals $U^{E}+V^{E}=\beta\left(y_{m}+y_{f}\right)^{\alpha}\left(w_{m} y_{m}+w_{f} y_{f}\right)$ when $w_{m} y_{m}=w_{f} y_{f}$. Thus we have

$$
\frac{\partial^{2}\left(U^{E}+V^{E}\right)}{\partial y_{m} \partial y_{f}}= \begin{cases}\alpha y_{f}^{\alpha-1} w_{m} & \text { if } w_{m} y_{m}>w_{f} y_{f} \\ \alpha y_{m}^{\alpha-1} w_{f} & \text { if } w_{m} y_{m}<w_{f} y_{f} \\ \frac{\alpha 2^{-(1+\alpha)}}{\left(y_{f}+y_{m}\right)^{2-\alpha}}\left[\left(\alpha w_{f}+w_{m}\right) y_{f}+\left(\alpha w_{m}+w_{f}\right) y_{m}\right] & \text { if } w_{m} y_{m}=w_{f} y_{f}\end{cases}
$$

Since equation (9.1.1) is strictly positive in all three cases, spousal matching will be assortative when households reach efficient decisions.

\subsection{Proof of Proposition 3:}

For heuristic purposes and without loss of generality suppose that the endowment distribution functions $G\left(y_{m}\right)$ and $H\left(y_{f}\right)$ are identical.

(i) Suppose not. Suppose that, $\forall\left(y_{m}^{*}, y_{f}^{*}\right)$, couples do not specialize and $l_{m}^{E}=l_{f}^{E}=$ $\alpha /(1+\alpha), h=\left[\alpha\left(y_{m}^{*}+y_{f}^{*}\right) /(1+\alpha)\right]^{\alpha}, c_{f}^{E}+c_{m}^{E}=\left(w_{m} y_{m}^{*}+w_{f} y_{f}^{*}\right) /(1+\alpha)$ and $U^{E}+V^{E}$ $=\beta\left(y_{m}^{*}+y_{f}^{*}\right)^{\alpha}\left(w_{m} y_{m}^{*}+w_{f} y_{f}^{*}\right)$. Then, given that $r<1$, the husbands in lowest-ranked marriages have an endowment equal to $y_{m}^{0}$ and their wives have $\gamma, \gamma<y_{m}^{0}$. Due to the fact $r<1$, that there are also single men with endowments equal to $y_{m}^{0}$. Both the husbands in lowest-ranked marriages and single men with $y_{m}^{0}$ endowments get the utility $U^{S}=\beta w_{m}\left(y_{m}^{0}\right)^{1+\alpha}$. The wives in lowest-ranked marriages capture all of the surplus and gets $V=\beta\left(y_{m}^{0}+\gamma\right)^{\alpha}\left(w_{m} y_{m}^{0}+w_{f} \gamma\right)-\beta w_{m}\left(y_{m}^{0}\right)^{1+\alpha}$. Due to non-specialization, this utility level is strictly less than the Pareto efficient level given by Remark 3: $U^{E}+V^{E}$ $-U^{E S}=y_{m}^{0}\left[\gamma^{\alpha} w_{m}-\beta w_{m}\left(y_{m}^{0}\right)^{\alpha}\right]$. Now if a single man with $y_{m}^{0}$ endowment is offered $U^{S}+\varepsilon, \varepsilon>0$, by a woman with an endowment of $\gamma$, they would both be strictly better off via specialization. In addition, since there will always be a man with the endowment of $y_{m}^{0}$ that remains single in equilibrium, the necessary transfer amount, $\varepsilon$, will equal 
zero in equilibrium. This verifies that non-cooperative behavior is not sustainable as a marriage market outcome among couples of the lowest assortative rank. By a simple logical extension, we can verify that, if this is the case, no couple of higher rank can sustain non-cooperative equilibrium behavior. In particular, suppose that, $\forall\left(y_{m}^{*}, y_{f}^{*}\right)$, allocations are made efficiently but that $\exists\left(\hat{y}_{m}, \hat{y}_{f}\right), \hat{y}_{m}=y_{m}^{*}+\mu_{m}$ and $\hat{y}_{f}=y_{f}^{*}+\mu_{f}$, $\mu_{i}, i=f, m$, whose allocations are determined non-cooperatively. The allocations of all couples $\left(y_{m}^{*}, y_{f}^{*}\right)$ would satisfy Proposition 1 whereas those of any couple $\left(\hat{y}_{m}, \hat{y}_{f}\right)$ would not. Hence, for small enough $\mu_{i}$ the couple $\left(\hat{y}_{m}, \hat{y}_{f}\right)$ would be made strictly better off by matching with a partner with an endowment of $y_{i}^{*}$ and allocating resources efficiently. Moreover, all individuals with $y_{i}^{*}$ would be willing to take such offers because of the higher endowment of the potential partner, which equals $\hat{y}_{i}$. Thus, we verify that, as long as $r<1$ and $w_{m} y_{m}>w_{f} y_{f} r \neq 1, \forall\left(y_{m}^{*}, y_{f}^{*}\right)$, allocations would be made efficiently.

(ii) Proof of efficient allocations when $r>1$ and $w_{m} y_{m}<w_{f} y_{f}$ is similar to the case above. The only difference is that now women ought to specialize in market production and men should solely do homework. Without such specialization men would receive $U=\beta\left(\gamma+y_{f}^{0}\right)^{\alpha}\left(w_{m} \gamma+w_{f} y_{f}^{0}\right)-\beta w_{f}\left(y_{f}^{0}\right)^{1+\alpha}$. This utility level is strictly less than the Pareto efficient level given by Remark 3: $U^{E}+V^{E}-V^{E S}=y_{f}^{0}\left[\gamma^{\alpha} w_{f}-\beta w_{f}\left(y_{f}^{0}\right)^{\alpha}\right]$. As in case (i), if a single woman with $y_{f}^{0}$ endowment is offered $V^{S}+\varepsilon, \varepsilon>0$, by a man with an endowment of $\gamma$, they would both be strictly better off via specialization. In addition, since there will always be a woman with the endowment of $y_{f}^{0}$ that remains single in equilibrium, the necessary transfer amount, $\varepsilon$, will equal zero in equilibrium. This verifies that non-cooperative behavior is not sustainable as a marriage market outcome among couples of the lowest assortative rank. By a simple logical extension, we can verify that, if this is the case, no couple of higher rank can sustain non-cooperative equilibrium behavior.

(iii) Since only efficient choices can be sustained as the marriage market equilibrium when either $r<1$ and $w_{m} y_{m}>w_{f} y_{f}$ or $r>1$ and $w_{m} y_{m}<w_{f} y_{f}$, it follows that spousal allocations satisfy Proposition 1. Those allocations are functions only of wages, endowments, $k, k^{\prime}$, and $r$. The latter three variables are determined solely by the distribution 
of spousal endowments, $G$ and $H$, and the sex ratio $r$. 


\section{References}

Baker, M. J. and J. P. Jacobsen. (2003). "Marriage, Specialization, and the Gender Division of Labor," University of Connecticut, unpublished manuscript.

Basu, K. (2001). "Gender and Say: A Model of Household Behavior with EndogenouslyDetermined Balance of Power," Cornell University, unpublished manuscript.

Becker, G. S. (1981). A Treatise on the Family, (MA: Harvard University Press).

Becker, G. S. and K. M. Murphy. (2000). Social Economics, (MA: Harvard University Press).

Bourguignon, F. and P. Chiappori. (1994). "The Collective Approach to Household Behavior," in R. Blundell, I. Preston, and I. Walker eds., The Measurement of Household Welfare, (Cambridge, U.K.: Cambridge University Press).

Browning, M., F. Bourguignon, P. A. Chiappori, and V. Lechene. (1994). "Income and Outcomes: A Structural Model of Intrahousehold Allocation," Journal of Political Economy, 102 (6), 1067-96.

Browning, M., P. A. Chiappori, and V. Lechene. (2004). "Collective and Unitary Models: a Clarification," Oxford University, unpublished manuscript.

Browning, M., P. A. Chiappori, and Y. Weiss. (2003). "A Simple Matching Model of the Marriage Market," University of Chicago, unpublished manuscript.

Chiappori, P. A. (1988). "Rational Household Labor Supply," Econometrica, 56, 6390.

Chiappori, P. A. (1992). "Collective Labor Supply and Welfare," Journal of Political Economy, 100 (3), 437-67.

Chiappori, P. A. (1997). "Introducing Household Production in Collective Models of Labor Supply," Journal of Political Economy, 105, 191-209.

Chiappori, P. A., B. Fortin, and G. Lacroix. (2002). "Marriage Market, Divorce Legislation, and Household Labor Supply," Journal of Political Economy, 110 (1), 37-72.

Chiappori, P. A., M. Iyigun, and Y. Weiss. (2004). "Spousal Matching, Divorce 
Legislation and Endogenous Sharing Rules," University of Colorado, Boulder, unpublished manuscript.

Chiappori, P. A., M. Iyigun, and Y. Weiss. (2005). "Marriage Markets, Spousal Specialization and Intra-Household Allocations," University of Colorado, Boulder, in progress.

Chiappori, P. A. and Y. Weiss. (2000). "Marriage Contracts and Divorce: An Equilibirum Analysis," University of Chicago, unpublished manuscript.

Chiappori, P. A. and Y. Weiss. (2004). "Divorce, Remarriage and Child Support," Tel Aviv University, unpublished manuscript.

Daniel, K. (1992). "Does Marriage Make Men More Productive?," Economic reserach Center (NORC), Working Paper Series, No: 92-2.

Gronau, R. (1986). "Home Production-a Survey" in O. Ashenfelter and R. Layard, eds., Handbook of Labor Economics, Volume 1A, (Amsterdam: North-Holland).

Hadfield, G. K. (1999). "A Coordination Model of the Sexual Division of Labor," Journal of Economic Behavior and Organization, 40 (2), 125-53.

Iyigun, M. and R. P. Walsh. (2002). "Endogenous Gender Power, Labor Supply, and the Quantity-Quality Tradeoff," University of Colorado, unpublished manuscript.

Iyigun, M. and R. P. Walsh. (2004). "Building the Family Nest: A Collective Household Model with Competing Pre-Marital Investments and Spousal Matching," University of Colorado, unpublished manuscript.

Korenman, S. and D. Neumark. (1992). "Marriage, Motherhood, and Wages," Journal of Human Resources, 27, 233-55.

Lundberg, S. and R. A. Pollak. (1993). "Separate Spheres Bargaining and the Marriage Market," Journal of Political Economy, 101 (6), 988-1010.

Lundberg, S. and R. A. Pollak. (1994). "Non-Cooperative Bargaining Models of Marriage," American Economic Review, 84 (2), May.

Lundberg, S. and R. A. Pollak. (2003). "Efficiency in Marriage," Review of Economics of the Household, September. 
Manser, M. and M. Brown. (1980). "Marriage and Housheold Decision-Making: A Bargaining Analysis," International Economic Review, 21, February, 31-44.

McElroy, M. B. and M. J. Horney. (1981). "Nash-Bargained Decisions: Towards a Generalization of the Theory of Demand," International Economic Review, 22, June, $333-49$.

Peters, M. and A. Siow. (2002). "Competing Pre-Marital Investments," Journal of Political Economy, 110 (3), 592-608.

Samuelson, P. (1956). "Social Indifference Curves," Quarterly Journal of Economics, $70(1), 1-22$.

Sen, A. (1983). "Economics and the Family," Asian Development Review, 1, 14-26.

Udry, C. (1996). "Gender, the Theory of Production, and the Agricultural Household," Journal of Political Economy, 104 (5), October, 1010-46.

Weiss, Y. (1997). "The Formation and Dissolution of Families: Why Marry? Who Marries Whom? And What Happens in Divorce?" in M. Rosenzweig and O. Stark, eds. Handbook of Population and Family Economics, Volume 1A, (Amsterdam: Elsevier Publishers). 
Figure 1: The Marital Matching Function

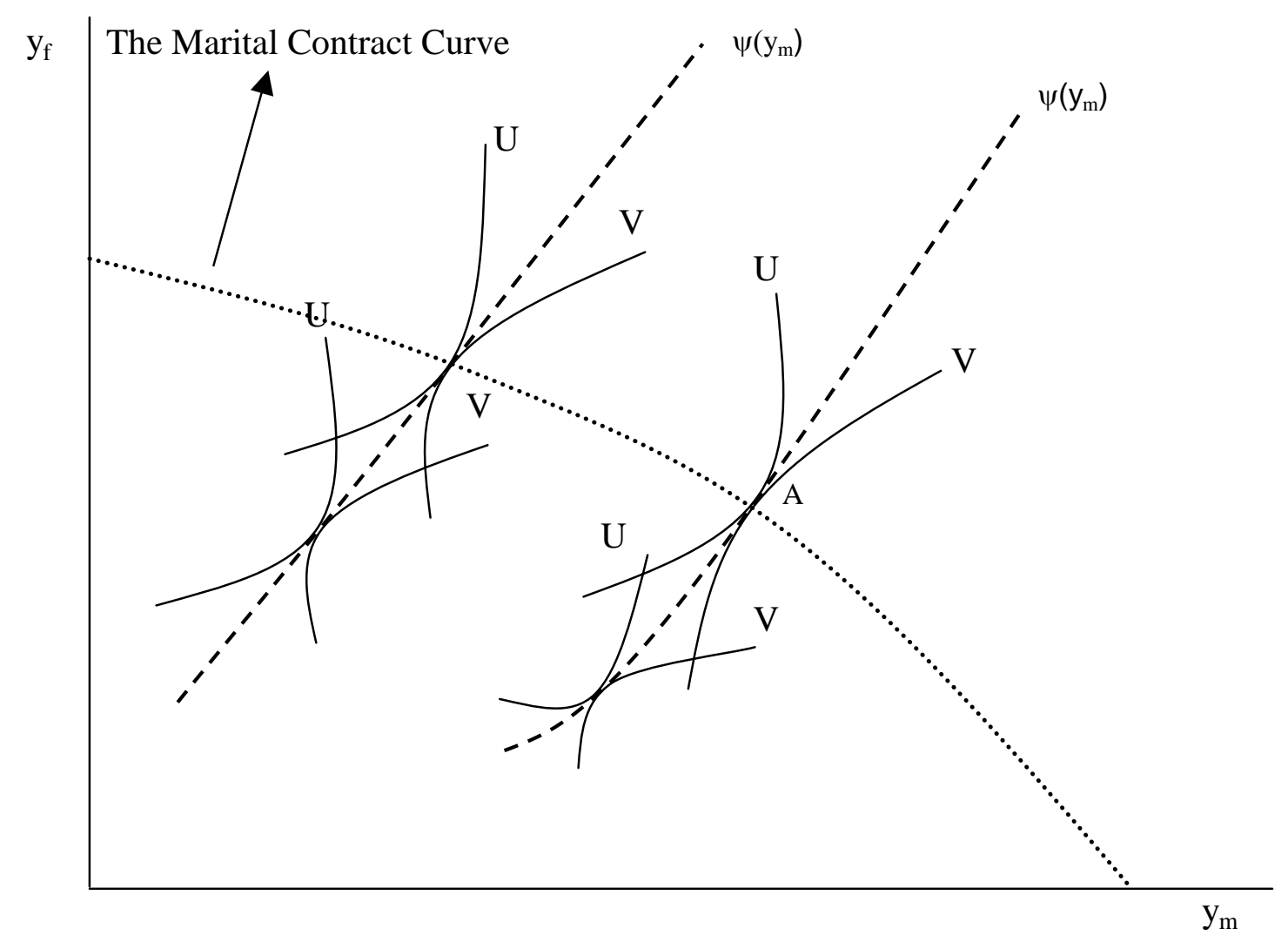


Figure 2: The Marital Contract Curve and the Efficient Frontier

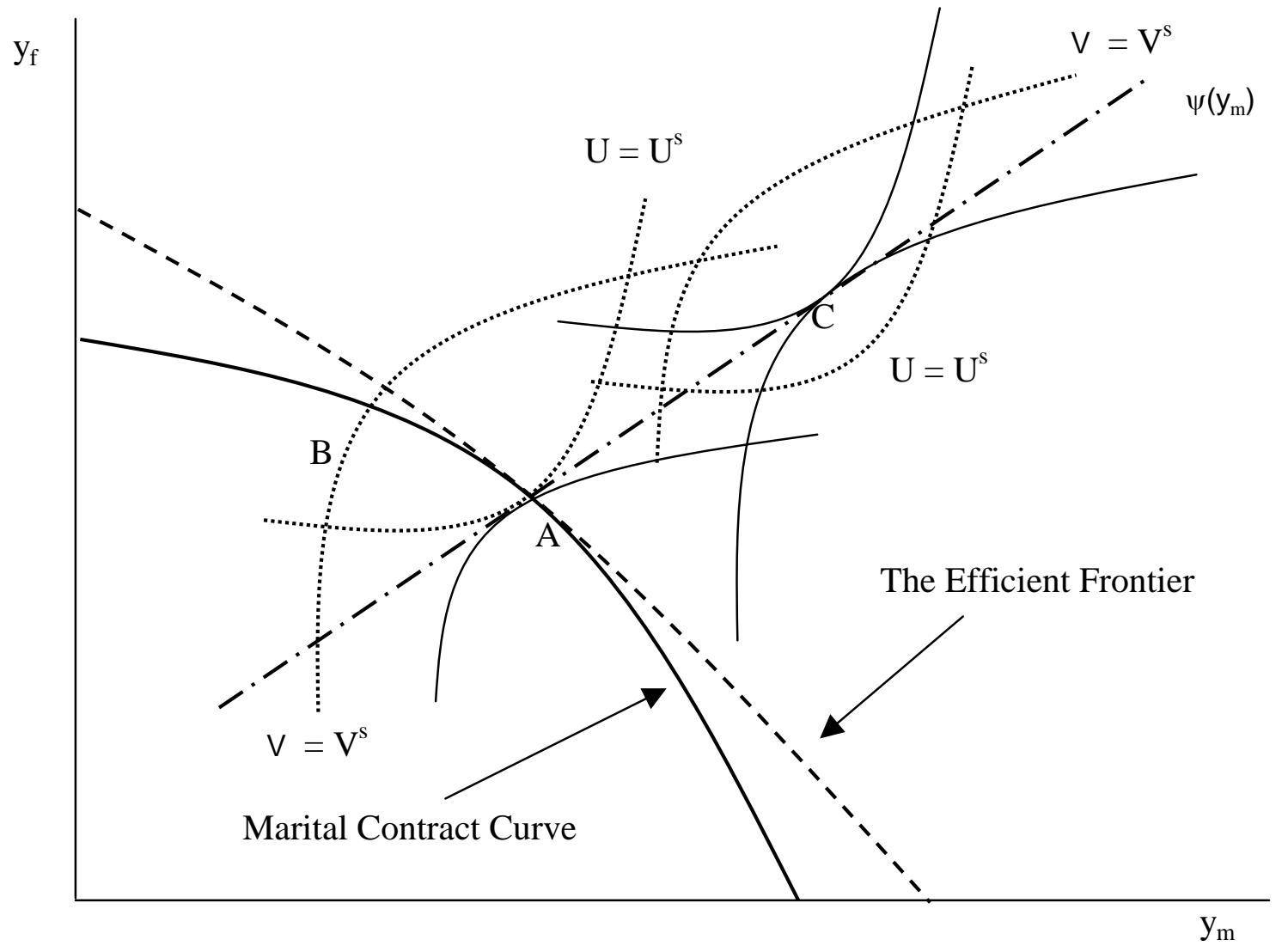

